\title{
Frequency of thrombocytopenia and its association with mortality among neonates having probable or culture proven sepsis.
}

1. MBBS, DCH,

FCPS (Peads Medicine)

Associate Professor Pediatrics

DG Khan Medical College, DG Khan.

2. MBBS, FCPS (Peds Medicine) Assistant Professor Pediatrics Nishtar Medical University Hospital, Multan.

3. MBBS, FCPS (Obs \& Gyn) Consultant Gynaecologist THQ Hospital Kot Chutta, Dera Ghazi Khan.

4. MBBS, FCPS (Paeds Medicine) Senior Registrar Paediatrics Nishtar Medical University and Hospital, Multan.

Correspondence Address:

Dr. Shakeel Ahmad

Department of Pediatric Medicine DG Khan Medical College, DG Khan. dr_leghari190@hotmail.com

Article received on: 28/01/2020

Accepted for publication: $29 / 06 / 2020$

\section{INTRODUCTION}

Sepsis possess major burden in terms of morbidity and mortality among newborns. ${ }^{1}$ Hematological changes induced by culture proven and probable neonatal sepsis have been used to make early diagnosis and to detect complications. Beside other hematological findings, changes in platelet count and platelet indices induced by neonatal sepsis have been the focus of many studies. ${ }^{2,3}$

Among neonates, thrombocytopenia (TCP) is amongst the earliest yet non-specific marker of sepsis with or without disseminated intravascular coagulation (DIC). TCP may be due to bacterial, viral, fungal or parasitic infections and other noninfectious causes. ${ }^{4,5}$ Overall prevalence of TCP has been noted to be 1 to $5 \%$ among neonates while it can be as high as $35 \%$ in neonates admitted to neonatal intensive care units (NICUs) ${ }^{6-10}$ Severe TCP (platelets count $<50000 /$ $\mathrm{mm} 3$ ) has been observed in $2.4 \%$ neonates admitted in NICU. Bleeding is known to be an important complication of TCP but is usually seen in infants having platelets count $<30000 / \mathrm{mm} 3$. Among culture proves sepsis, researchers have found around $50 \%$ of the cases to have TCP. ${ }^{11,12}$

In patients suffering from different diseases, TCP have been found to be linked with raised mortality. 4,13 There was a need to ascertain whether TCP with culture proven or probable neonatal sepsis has association with increased mortality or not. This study was done to find out frequency of TCP and its association with mortality among neonates having probable or culture proven sepsis.

\section{MATERIAL \& METHODS}

It was a descriptive analytical study conducted at the NICU of Nishter Medical University Multan and DHQ Teaching Hospital, Dera Ghazi Khan from Feb. 2019 to July 2019. 
Ethical and research committee of DHQ Teaching Hospital D.G.Khan and Nishter Medical University Multan approved the study. Informed consent was sought from the parents/guardians of all study participants.

A total of 342 (142 from DHQ DG Khan and 200 from Nishtar Medical University Multan) neonates presented and admitted with sepsis at study places during the study period were enrolled. Neonatal sepsis was labeled as, aged from birth to 28 days, presenting with clinical signs and symptoms of sepsis along with isolation of pathogen from blood, cerebrospinal fluid (CSF) or urine. e. Probable sepsis was labeled4 as neonates having clinical signs and symptoms of sepsis, in the absence of growth of any pathogen from blood, urine or cerebrospinal fluid but presented with at least one or more than one of these: (i) leukocyte count $>30,000 /$ $\mathrm{mm}^{3}$ or leukocyte count $<5,000 / \mathrm{mm}^{3}$ or CRP more than $6 \mathrm{ug} / \mathrm{ml}$, (ii) presence of maternal fever or foul smelling liquour or prolonged rupture of membreans (more than 12 hours) or presence of polymorphic leukocyest (> 5 leukocytes per high power field). ${ }^{4}$ Neonates having congenital heart diseases or congenital anomalies, hypoxicischemic encephalopathy or hyaline membrane disease were not included.

Blood samples of all cases were obtained for complete blood count, C-reactive protein levels and blood cultures. Urine sample of all the patients were sent for routine examination and culture. Lumbar puncture was done among neonates having signs and symptoms of meningitis. CSF of these cases was sent for microscopic examination, gram staining, protein and glucose levels, and culture.

A predesigned proforma was used to record information like name, gender, age along with white blood cells (WBC) count, platelet count, CRP levels, blood culture reports, urine routine and culture reports, CSF reports, and mortality data. Thrombocytopenia was taken as platelet count $<150000 / \mathrm{mm}^{3}{ }^{4}$ Appropriate antibiotic treatment was given to all neonates. Those with platelet count $<100000 / \mathrm{mm}^{3}$, received platelet transfusion, if bleeding was present. All patients who had platelet count $<30000 / \mathrm{mm} 3$ received platelet transfusion even in the absence of bleeding.

SPSS version 22 was employed seeking data analysis. Chi-square test was used to compare study variables in different groups, considering p-value of 0.05 or less as significant.

\section{RESULTS}

Out of a total of 342 neonates, 42 left against medical advice so those 42 neonates were excluded from the final analysis. Finally, 300 neonates were considered for final study analysis. Out of those 300 neonates, 164 (54.7\%) were male. Early onset sepsis or probable sepsis (presenting at $<7$ day age) was seen in 201 $(67.2 \%)$ cases, and late onset sepsis or probable sepsis (presenting at $>7$ day age) in 99 (32.8\%) cases. Overall, median platelet count was $213.0 \mathrm{~mm}^{3}$. TCP was present in $78(26.0 \%)$ cases.

Among 146 culture proven sepsis cases, 88 $(61.8 \%)$ had gram positive while 58 (38.2\%) had gram negative pathogens. No case was found to have fungal infection.

Table-I shows mortality rate in patients with thrombocytopenia and with normal or raised platelet count. Cases having thrombocytopenia had significantly higher mortality $(n=26 / 78$, $33.3 \%)$ as compared with those who had normal or increased platelet count $(n=25 / 222,11.3 \%)$ representing a significant $\mathrm{p}$ value $(<0.00001)$. Median platelet counts of that cases discharged and expired were $224.0 / \mathrm{mm} 3$ and $175.0 / \mathrm{mm} 3$ respectively.

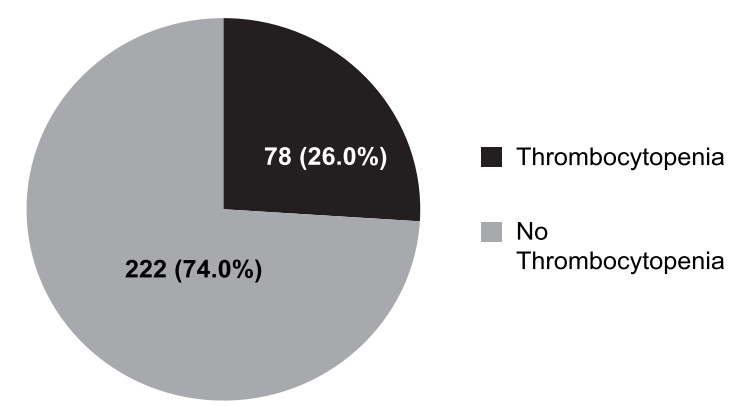

Figure-1. Frequency of thrombocytopenia $(n=300)$ 


\begin{tabular}{|l|c|c|c|}
\hline \multicolumn{1}{|c|}{ Group according to platelet count } & Discharged & Expired & P-Value \\
\hline Thrombocytopenia $<150000 / \mathrm{mm}^{3}$ & $52(66.7 \%)$ & $26(33.3 \%)$ & $<0.00001$ \\
\hline Normal or raised platelet count & $197(88.7 \%)$ & $25(11.3 \%)$ & \\
\hline
\end{tabular}

Table-I. Mortality rates in different groups with or without thrombocytopenia $(n=300)$

\section{DISCUSSION}

TCP is a frequent complication among neonates suffering from different diseases and has been shown to have higher rates of mortality. ${ }^{13-16}$ It is also a common complication of neonatal sepsis. ${ }^{17,18}$

We noted TCP to be present in $78(26.0 \%)$ cases. A study by Mannan MA and Colleagues found half of their cases with neonatal sepsis to have TCP. ${ }^{11}$ Guida JD and Coworkers ${ }^{12}$, analyzing very low birth weight neonates having culture proven sepsis, found $54 \%$ of the cases to have TCP. Our results were very similar to what Ahmad MS and Waheed $\mathrm{A}^{4}$ found where $24.7 \%$ of the neonates had TCP. Our results were also close to a study conducted by Madani MS et al ${ }^{2}$ from Iran where $20.0 \%$ of the neonates had TCP. A study by Bhat $\mathrm{RY}$ et $\mathrm{al}^{19}$ from India also noted higher prevalence of TCP among blood culture proven neonatal sepsis.

TCP has been documented to an independent marker for sepsis linked deaths. ${ }^{20}$ Vigorous platelets destruction with or without impaired platelet production could be the underlying issue defining TCP among neonates. ${ }^{21,22}$ We noted significantly more mortality among neonates having TCP. Very similar to our findings, Charro $\mathrm{BA}$ et $\mathrm{a}^{23}$ assessing neonates in their tertiary care unit found mortality rate was significantly associated with thrombocytopenia. Another study analyzing both probable and culture confirmed sepsis among neonates noted $24.7 \%$ cases to have TCP. ${ }^{4}$ Olmez et al ${ }^{24}$ showed that a more than $30 \%$ decline in platelet count was linked with higher rates of mortality. Another study by Rastoqi $S$ et $\mathrm{al}^{25}$ concluded that decrease in platelet count among preterm neonates is associated with increased mortality. Besides increased mortality rate, intraventricular hemorrhage $>$ grade 2 occurs more often in neonates with TCP but this is independent of severity of thrombocytopenia. ${ }^{26}$ This study showed that patients of probable and proven neonatal sepsis with TCP significantly suffer more mortality.

TCP is a common finding in pediatric age group. Essential thrombocytosis is extremely rare. ${ }^{27}$ A study conducted by Fouzas $S$ et $a^{28}$ showed that reactive thrombocytosis was a common observation among children having serious bacterial infections while reactive thrombocytosis was also marked important for early recognition among febrile young infants who are having increased risk of serious bacterial infections. Many conditions can lead to reactive thrombocytosis. Both viral and bacterial infections can lead to reactive thrombocytosis. Infections of respiratory tract are the commonest cause followed by infections of urinary tract, gastrointestinal tract and meningitis. Besides infections, iron deficiency anemia, hemolytic anemias, bleeding, connective tissue disorders, malignancies, trauma and various drugs can also leads to thrombocytosis. It is more common especially in premature neonates, and in children up to 2 years. Reactive thrombocytosis in children does not require treatment with platelet aggregation inhibitors, even if the platelet count is greater than $1,000,000 / u l$, unless additional thrombophilic risk factors exist. ${ }^{27,29}$ Therefore, treatment needs to be focused towards underlying etiology.

This was a multicenter study from 2 leading institutions of South Punjab but our study had few limitations as well. We could not monitor platelets count on regular basis during hospital stay among participants of this study. Monitoring platelets count on regular basis would have given us a better opportunity to further analyze various other aspects regarding this study. This could not be done due to financial and administrative constraints.

\section{CONCLUSION}

Thrombocytopenia is a common complication of culture proven and probable neonatal sepsis. 
Mortality is significantly high in neonatal sepsis along with thrombocytopenia.

\section{ACKNOWLEDGEMENT}

The authors would like to thank Muhammad Aamir from Bahawalpur, Pakistan, for his valuable assistance in statistical analysis.

Copyright@ 29 June, 2020.

\section{REFERENCES}

1. Grant $\mathrm{CH}$, Arnott A, Brook T, Horne A2, Hurst W2, Kelly $S$, et al. Reducing antibiotic exposure in suspected neonatal sepsis. Clinical Pediatrics (Phila) 2018; 57(1):76-81.

2. Madani SM, Amiri S, Khazaei S, Erfan MB, Rostami-Far $Z$, Tarlan $M$, et al. Platelet indices as useful indicators of neonatal sepsis. J. Evolution Med. Dent. Sci. 2019; 8(20); 1612-7.

3. Ree IMC, Fustolo-Gunnink SF, Bekker V, Fijnvandraat KJ, Steggerda SJ, Lopriore E. Thrombocytopenia in neonatal sepsis: Incidence, severity and risk factors. PLoS ONE 2017; 12(10):e0185581.

4. Ahmad MS, Waheed A. Platelet Counts, MPV and PDW in culture proven and probable neonatal sepsis and association of platelet counts with mortality rate. $\mathrm{J}$ Coll Physicians Surg Pak 2014; 24 (5):340-4.

5. Stanworth SJ, Clarke P, Watts T, Ballard S, Choo L, Morris T, et al. Prospective, observational study of outcomes in neonates with severe thrombocytopenia. Pediatrics. 2009; 124(5):e826-34.

6. Roberts I, Stanworth S, Murray NA. Thrombocytopenia in the neonate. Blood Rev 2008; 22:173-86.

7. Sola-Visner M, Saxonhouse MA, Brown RE. Neonatal thrombocytopenia: what we do and don't know. Early Hum Dev 2008; 84:499-506.

8. Shaikh QH, Ahmad SM, Abbasi A, Malik SA, Sahito AA, Munir SM. Thrombocytopenia in malaria. J Coll Physicians Surg Pak 2009; 19:708-10.

9. Ferrer-Marin F, Liu ZJ, Gutti R, Sola-Visner M. Neonatal thrombocytopenia and megakaryocytopoiesis. Semin Hematol 2010; 47:281-8.

10. Baer VL, Lambert DK, Henry E, Christensen RD. Severe thrombocytopenia in the NICU. Pediatrics 2009; 124:e1095-100.

11. Mannan MA, Shahidullah M, Noor MK, Islam F, Alo $D$, Begum NA. Utility of creative protein and hematological parameters in the detection of neonatal sepsis. Mymensingh Med J 2010; 19:259-63.
12. Guida JD, Kunig AM, Leef KH, McKenzie SE, Paul DA. Platelet count and sepsis in very low birth weight neonates: Is there an organism-specific response? Pediatrics 2003; 111:1411-5.

13. Stephan F, Hollande J, Richard O. Thrombocytopenia in a surgical intensive care unit: Incidence, risk factors and outcome. Chest 1999; 115:1363-70.

14. Stephan F, de Montblanc J, Cheffi A, Bonnet F. Thrombocytopenia in critically ill surgical patients: A case-control study evaluating attributable mortality and transfusion requirements. Critical Care 1999; 3:151-8.

15. Baughman RP, Lower EE, Flessa HC, Tollerud DJ. Thrombocytopenia in the intensive care unit. Chest 1993; 104:1243-7.

16. Hanes SD, Quarles DA, Boucher BA. Incidence and risk factors of thrombocytopenia in critically ill trauma patients. Ann Pharmacother 1997; 31:285-9.

17. Simmons J, Pittet JF. The coagulopathy of acute sepsis. Current Opinion in Anaesthesiology 2015; 28(2):227-36 .

18. Guclu E, Durmaz Y, Karabay O. Effect of severe sepsis on platelet count and their indices. African Health Sciences 2013; 13(2):333-8.

19. Bhat RY, Kousika P, Lewis L, Purkayastha J. Prevalence and severity of thrombocytopenia in blood culture proven neonatal sepsis: A prospective study. Arch Pediatr Infect Dis. 2018; 6(2):e12471.

20. Levit O, Bhandari V, Li FY, Shabanova V, Gallagher $P G$, Bizzarro MJ. Clinical and laboratory factors that predict death in very low birth weight infants presenting with late-onset sepsis. Pediatr Infect Dis J. 2014; 33(2):143-6.

21. Brown RE, Rimsza LM, Pastos K, Young L, Saxonhouse MA, Bailey $M$, et al. Effects of sepsis on neonatal thrombopoiesis. Pediatr Res. 2008; 64(4):399-404.

22. Roberts IA, Murray NA. Neonatal thrombocytopenia: New insights into pathogenesis and implications for clinical management. Curr Opin Pediatr. 2001; 13(1):16-21.

23. Charoo BA, lqbal Jl, Iqbal Q, Mushtaq S, Bhat AW, Nawaz I. Nosocomial sepsis induced late onset thrombocytopenia in a neonatal tertiary care unit: A prospective study. Hematol Oncol Stem Cell Ther 2009; 2:349-53. 
24. Olmez I, Zafar M, Shahid M, Amarillo S, Mansfield R. Analysis of significant decrease in platelet count and thrombocytopenia, graded according to $\mathrm{NCI}-\mathrm{CTC}$, as prognostic risk markers for mortality and morbidity. J Pediatr Hematol Oncol 2011; 33:585-8.

25. Rastoqi S, Olmez I, Bhutada A, Rastogi D. Drop in platelet counts in extremely preterm neonates and its association with clinical outcomes. J Pediatr Hematol Oncol 2011; 33:580-4.

26. Von Lindern JS, van den Bruele T, Lopriore E, Walther FJ. Thrombocytopenia in neonates and the risk of intraventricular hemorrhage: A retrospective cohort study. BMC Pediatr 2011; 11:11-6.
27. Yadav D, Chandra J, Sharma S, Singh V. Essential thrombocytosis and antiphospholipid antibody syndrome causing chronic Budd-Chiari syndrome. Indian J Pediatr 2012; 79:538-40.

28. Fouzas S, Mantagou L, Skylogianni E, Varvarigou A. Reactive thrombocytosis in febrile young infants with serious bacterial infection. Indian Pediatr 2010; 47:937-43.

29. Mantadakis E, Tsalkidis A, Chatzimichael A. Thrombocytosis in childhood. Indian Pediatr 2008; 45:669-77.

\begin{tabular}{|c|c|c|c|}
\hline \multicolumn{4}{|c|}{ AUTHORSHIP AND CONTRIBUTION DECLARATION } \\
\hline Sr. \# & Author(s) Full Name & Contribution to the paper & Author(s) Signature \\
\hline 1 & Shakeel Ahmad & Study idea, Design, Supervision. & Trikal. \\
\hline 2 & Nusrat Hussain & $\begin{array}{l}\text { Data collection, Literature review, } \\
\text { Proof reading. }\end{array}$ & Ausn \\
\hline 3 & Tayyaba Rafique & Data analysis, Discussion, Drafting. & Tayyans: \\
\hline 4 & Rabia Saleem & Data collection, Data interpretaion. & 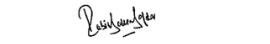 \\
\hline
\end{tabular}

